\title{
Defining minimum runoff length allows for discriminating biocrusts and rainfall events
}

\author{
Roberto Lázaro $^{1 *}$, Adolfo Calvo-Cases ${ }^{2}$, Eva Arnau-Rosalén ${ }^{3}$, Consuelo Rubio ${ }^{1}$, David Fuentes ${ }^{4,5}$, \\ Clément López-Canfín ${ }^{1,6}$
}

${ }^{1}$ Estación Experimental de Zonas Áridas (CSIC), Carretera Sacramento s/n, 04120 La Cañada, Almería, Spain.

${ }^{2}$ Inter-University Institute for Local Development (IIDL), Department of Geography, University of Valencia, Edifici d'Instituts, $4^{a}$ Planta C/ Serpis 29, 46022, València, Spain.

${ }^{3}$ Department of Natural Sciences, Manchester Metropolitan University, John Dalton Building E410a, Chester Street, Manchester M1 5GD, UK.

${ }^{4}$ Department of Ecology, University of Alicante, C/ de San Vicente del Raspeig, s/n, 03690 San Vicente del Raspeig, Alicante, Spain.

${ }^{5}$ Ecodrone Works, C/ Señores Maripino Rosello, 4, 03550, Sant Joan d'Alacant, Spain.

${ }^{6}$ Departamento de Física Aplicada, Universidad de Granada, Avenida Fuente Nueva s/n, 18071 Granada, Spain.

* Corresponding author. E-mail: lazaro@eeza.csic.es

\begin{abstract}
The runoff coefficient (RC) is widely used despite requiring to know the effective contributing area, which cannot be known a priori. In a previous work, we defined runoff length (RL), which is difficult to measure. This work aimed to define the minimum RL (mRL), a quantitative and easy proxy of RL, for use in a pilot study on biocrusts in the Tabernas Desert, Spain. We show that RC decreases according to a hyperbola when the contributing area increases, the independent variable being the length of the effective contributing area and its coefficient involving the effects of rainfall and surface features and antecedent conditions. We defined the $\mathrm{mRL}$ as the length of the effective contributing area making $\mathrm{RC}=1$, which is calculated regardless of the area. We studied mRL from three biocrust types and 1411 events clustered in seven categories. The mRL increased with rain volume and intensity, catchment area and slope, whereas plant cover and biocrust succession (with one exception) had a negative effect. Depending on the plot, mRL reached up $3.3-4.0 \mathrm{~m}$ on cyanobacterial biocrust, $2.2-7.5 \mathrm{~m}$ on the most widespread lichens, and $1.0-1.5 \mathrm{~m}$ on late-successional lichens. We discuss the relationships of $\mathrm{mRL}$ with other runoff-related parameters.
\end{abstract}

Keywords: Semiarid; Biological soil crust; Runoff connectivity; Length slope factor; Infiltration; Tabernas Desert.

\section{INTRODUCTION}

Abundant evidence shows that runoff is highly dependent on rainfall features (volume and intensity), surface hydrological properties (vegetation, biocrust, litter, stones, and other soil surface components), soil characteristics (texture, porosity, and organic matter), previous soil conditions (antecedent soil moisture), and topography (slope angle and contributing area). To study and compare the effects of these multiple factors controlling runoff, the runoff coefficient $(\mathrm{RC})$ is a widely used parameter.

Nevertheless, using the RC, requires knowing the contributing area. Closed runoff plots (surrounded by a wall delimiting the monitored drainage area) have been widely used under the assumption that the complete delimited area is the effective drainage area. Because this assumption is unfounded (Kidron and Yair, 1997; Kidron, 2011), delimiting an area does not make sense and, open runoff plots are preferable because they do not alter the natural fluxes and prevent the relative exhaustion of sediments (Boix-Fayos et al., 2006). However, using open runoff plots, we continue without knowing the effective contributing area, even if we topographically delimit an area in situ, which would be the maximum possible contributing area. Thus, we should assume that we never know $a$ priori the real drainage area corresponding to a runoff measurement nor, consequently, the real RC. Therefore, we need an alternative parameter enabling characterisation of the hydrological behaviour.
Non-concentrated runoff seems to form a continuous water sheet on the soil surface during rainfall, whereas infiltration occurs simultaneously in a spatially irregular manner dependent on the distribution of soil features. However, although the water sheet completely occupies a surface, runoff does not travel an undefined length because there is evidence that RC considerably decreases while the considered area increases (Kidron, 2011; Mayor et al., 2011; Xu et al., 2009). The farther a water input occurs from a runoff collector, the lower the amount of that input is collected. According to Lázaro et al. (2015), runoff length (RL) is the length of the hillslope travelled by runoff; that is, for any point, RL is the maximum distance, in a straight line following the maximum slope line, from which the runoff comes. (RL is different from the length of the path travelled by water, which depends on the surface microtopography). RL is important because it (i) contains some information on the hydrological connectivity, because at least the drainage area delimited by RL is necessarily fully connected; (ii) enables efficient comparisons of the hydrological properties of different surface types, rainfall types, and minimum inter-event times (MITs), etc., at least because it allows for determining the drainage area by its length; (iii) provides information on the sediment transport capacity; and (iv) seems to have potential to enable predictions about runoff flow at a point as a function of rainfall.

However, because RL cannot be directly observed, the RL concept is elusive. Little is known about the RL values in given circumstances, although Agassi and Ben-Hur (1991) studied the 
effect of slope length on infiltration and runoff. Puigdefábregas et al. (1999) and Arnau-Rosalén et al. (2008) suggested that the slope length travelled by runoff is often only a part of the catchment length. This idea also underlies the work of Puigdefábregas (2005), who stated that temporal variability of rainfall controls runoff re-infiltration and its decay with slope length. Lázaro et al. (2015) experimentally determined RL on biocrusts, although at only $1 \mathrm{~m}$ of spatial resolution. However, such experiments were logistically complex and time consuming. Here, we propose a high-resolution, quantitative subrogate of RL that is simple and easy to measure, using data from the same study area.

Biocrusts are complex communities constituted by microorganisms, lichens, bryophytes, fungi, and algae inhabiting the soil surface and within the upper soil centimetres. They are widespread on a planetary scale (Büdel, 2003) at the sites where vascular plants are limited by climatic factors, and they play an important ecological role because they affect almost every ecological process (Belnap and Lange, 2003; Maestre et al., 2011; Webber et al., 2016). Chamizo et al. (2016) published a review on the biocrusts' hydrological role. Biocrusts constitute a good system model (Bowker et al., 2010; Maestre et al., 2016) as well as adequate surface cover to study runoff due to the existence of previous experimental studies in the same area (e.g., Chamizo et al., 2012a; Lázaro and Mora, 2014; SoléBenet et al., 1997). On the other hand, biocrusts develop in plant interspaces where vegetation cannot form a continuous layer (mostly in drylands), and they are considered runoff sources, providing water to the plant patches (RodríguezCaballero et al., 2014; 2018). Thus, knowing their RL would provide insights to advance the current source-sink theory.

The initial hypotheses were as follows:

a) $\mathrm{RL}$ is often much shorter than the topographical drainage area, which represents the historical maximum of RL. Kidron and Yair (1997), Puigdefábregas et al. (1999), and Puigdefábregas (2005) and Arnau-Rosalén et al. (2008) already made suggestions in this line.

b) RL widely varies across numerous factors, such as the rainfall features (intensity, volume and timing), the surface characteristics (including vegetation, soil, topography, biocrusts, and stoniness), and the antecedent soil moisture. Because runoff strongly depends on these factors (Castillo et al., 2003; Le Bissonnais et al., 1995), we assume that RL will also depend on them.

c) In the study area, RL will be centimetres long rather than metres long for most natural rainfall (Lázaro et al., 2015), which very often has low intensity or small volume (Lázaro et al., 2001).

d) Biocrust will generally have high RC, but it will vary according to its species composition (Lázaro et al., 2015).

The objectives of this work were (i) to define the minimum RL (mRL) and propose it as a concrete, quantitative, and easy proxy of RL, and (ii) to use $\mathrm{mRL}$ for a pilot study to show the effect of biocrust type and rainfall class on RL from open runoff plots.

\section{METHODS}

\section{The study area and the runoff plots}

The Tabernas Desert is a place in southeast Spain, in the Sorbas-Tabernas basin, surrounded by the Gador, Nevada, Filabres, and Alhamilla Betic ranges. The first three of these ranges intercept most rainfall fronts, which come mainly from the west, explaining the annual precipitation of around $230 \mathrm{~mm}$ (Lázaro et al., 2001). Because the annual potential evapotran- spiration is around $1600 \mathrm{~mm}$, water deficit occurs every month, in particular during summer (June-September). Insolation is over 3000 hours per year, and the average annual temperature is $18{ }^{\circ} \mathrm{C}$ (Lázaro et al., 2004). The study area was the El Cautivo field site, within the Tabernas Desert. Although calcareous sandstones are locally abundant, Miocene soft marine marls dominate the lithology and produce an extensive badlands landscape and a complex geomorphology developed during the Quaternary (Alexander et al., 1994; Alexander et al., 2008). The parent material is mainly composed of silt-size $(>60 \%)$, gypsum-calcareous and siliceous particles; fine sand ranges from $20 \%$ to $35 \%$, and clay ranges from $5 \%$ to $10 \%$. (Cantón et al., 2003). El Cautivo includes a series of parallel catchments, with residual hanging pediments between some of them. A clear surface-type pattern exists. A third of the territory is bare and eroded; biocrust is the main cover in another third; and also occupies the plant interspaces in the rest (Cantón et al., 2004; Lázaro et al., 2000; Lázaro et al., 2008).

The biocrust types described by Lázaro et al. (2008) in this study area were simplified to three for this research: (i) dominated by Cyanobacteria (Cyano); (ii) dominated by the lichens Squamarina lentigera and/or Diploschistes diacapsis (Squam); and (iii) characterized by the lichen Lepraria isidiata (Lepra). The site of Cyano where the runoff plots were constructed has a mature, relatively rough cyanobacterial biocrust, including small pioneer lichens, such as Endocarpon pusillum, Fulgensia desertorum, and Fulgensia poelti. This biocrust is the colonizing one (beginning with a purely cyanobacterial biocrust) and is widespread in any orientation, constituting a matrix-like layer on which the other biocrust types successively develop when possible. In the sunniest non-eroded sites, Cyano is dominant and almost permanent. Squam is the most widespread lichen-dominated biocrust. It usually develops after Cyano, preferring the unaltered north-to-east hillslopes with low plant cover, and including numerous lichen species, such as Buellia zoharyi, Fulgensia fulgida, Diploschistes ocellatus, and Psora decipiens. Lepra biocrust is late successional and exclusive to the shadiest north-faced hillslopes, where it occupies the plant interspaces. Lichen species such as Squamarina carthilaginea, Xantoparmelia pokornyi, and Teloschistes lacunosus are characteristic of Lepra, as well as some mosses such as Grimmia pulvinata, Didymodon luridus, and Tortula revolvens.

\section{Runoff monitoring}

Two open runoff plots and a rain gauge were installed in each biocrust. The plots at Cyano were labelled $\mathrm{C} 1$ and $\mathrm{C} 2$, those of Squam S1 and S2, and those at Lepra L1 and L2. Their appearance is shown in Fig. 1. The available data cover approximately 10 years (2005-2015). Each plot consists of a PVC channel, normal to the line of maximum slope, collecting runoff and driving the water to a tank at the bottom of the hillslope. The channels, covered with a lid to avoid direct rain, are embedded into the soil, and the contact of its upslope edge with the soil was in situ plasticised by means of fiberglass and epoxy resin, warranting the transit of the runoff to the trough. Inside the tank is a non-purpose tipping-bucket mechanism $(0.5 \mathrm{~L}$ in resolution) connected to an on-off Hobo Event data logger, like that of the rain-gauge $(0.25 \mathrm{~mm}$ in resolution).

\section{Definition and calculation of $\mathbf{m R L}$}

Because the effective contributing area is not known a priori, examining the way $\mathrm{RC}$ varies in relation to it becomes essential. To conduct this theoretical examination, we used 
three minimum inter-event times (MITs): 24, 12, and 1 hour, constructing three datasets with 436, 593, and 1411 rainfall runoff events, respectively. For every event and each plot, we calculated four RC values by successively assuming different lengths $(1,2,3$, and $4 \mathrm{~m})$ for the effective contributing area. These hillslope lengths, multiplied by the width of the plot (length of the collector, $2.18 \mathrm{~m}$ except for L2, at $2.16 \mathrm{~m}$ ) gave rise to four nested, rectangular, and progressively larger supposed drainage areas per event, generating four RC figures. This procedure implies assuming that they were ideal smooth and homogeneous hillslopes. Our real plots only approximate these conditions, but this preliminary assumption is useful to explain the concept and calculation of mRL. Next, we applied this approach to real data, examining the way $\mathrm{RC}$ varies when successively larger portions of the real catchment are considered effective contributing areas.

As the width of the plot is assumed to remain constant for any channel length, the assumption of a series of hillslope lengths (for the supposed effective drainage area) increasing according to the series of natural numbers produces a series of nested areas, increasing in arithmetic progression. Because runoff must be divided by the area, while the plot length increases linearly, the corresponding RC potentially decreases because the value of a series of fractions with arithmetically increasing denominators decreases according to a potential curve of exponent -1 , forming a hyperbola. Thus, for any pair of runoff and precipitation values (i.e., for any rainfall or surface type and any slope angle), the RCs generated by assuming successively longer contributing areas always decrease according to the following curve:

$\mathrm{RC}=a \times x^{-1}$

where $x$ is the length of the part of the hillslope that is assumed to be the effective contributing area and $a$ is a coefficient that varies widely, because it involves the effects on runoff of the rainfall and surface characteristics, and can be experimentally calculated.

Thus, although we cannot calculate $\mathrm{RC}$, we can determine its distribution. Furthermore, for a rectangular plot, RC is as follows:

$\mathrm{RC}=\mathrm{R}_{(\mathrm{L})} /\left(\mathrm{P}_{(\mathrm{mm})} \times \mathrm{cW}(\mathrm{m}) \times \mathrm{x}_{(\mathrm{m})}\right)$

where $R_{(L)}$ is the runoff measured in litres, $P_{(\mathrm{mm})}$ is the measured precipitation in millimetres, $\mathrm{cw}_{(\mathrm{m})}$ is the width of the collector in metres, and $\mathrm{x}_{(\mathrm{m})}$ is the hillslope length of the supposed effectively contributing area in metres. Therefore, it is

$a=\mathrm{R}_{(\mathrm{L})} / \mathrm{P}_{(\mathrm{mm})} \times \mathrm{cW}_{(\mathrm{m})}$

These curves relating $\mathrm{RC}$ with the length of the contributing area for any event of any surface type are determined by only one parameter $(a)$. Any value for length leads to a value for RC that exactly matches a point in the hyperbola. Because the hyperbola has an indefinite length, a length of contributing area corresponding to $\mathrm{RC}=1$ always exists, independently from the surface and rain characteristics. As some infiltration always occurs, the actual RL will be larger than the hillslope length corresponding to $\mathrm{RC}=1$ is. Therefore, the hillslope length of the supposed effectively contributing area corresponding to $\mathrm{RC}=1$ can be considered the minimum RL (mRL) for the given set of circumstances (rainfall event, surface and antecedent conditions) and enables an easy definition for mRL. This means that the minimum hillslope length travelled by runoff for a certain site and event is larger than the mRL. RC hyperbola values that are larger than 1 simply mean that runoff comes from upslope of the length attributed to the drainage area. The larger than 1 the $\mathrm{RC}$ value is, the larger the $\mathrm{mRL}$ is in relation to the supposed length. As can be verified from Equation (1), when $\mathrm{RC}=1, x=a$. Therefore, we can define the following:

$\mathrm{mRL}_{(\mathrm{m})}=a=\mathrm{R}_{(\mathrm{L})} / \mathrm{P}_{(\mathrm{mm})} \times \mathrm{cW}_{(\mathrm{m})}$

Note that in Equation (4), only three known parameters intervene, and the contributing area does not.

To show these hyperbolic relationships, we used Equation (1) to plot the hyperbolas of the average (thus blurring the effect of the antecedent soil moisture) RC vs lengths successively assumed for the contributing area, for one plot of each biocrust type and two different rainfall classes. Later, to explore the effect of rainfall type on runoff, we classified the rainfall events into seven categories: $>0-1,>1-3,>3-5,>5-10,>10$ $20,>20-30$, and $>30 \mathrm{~mm}$. Because most of the rainfall events were small, we divided the group of events $\leq 5 \mathrm{~mm}$ into three classes to avoid an extremely large lower class and to gain resolution to establish the rainfall threshold generating runoff.

\section{Analysis of mRL at El Cautivo field site throughout biocrust types and rainfall events}

On natural hillslopes whose topography generates somewhat irregular drainage areas, in such a way that a regular increment in the length of the supposed effective catchment does not imply a regular increment in its area, the theoretical relationship in Equation (1) is only fulfilled in an approximate way and a potential curve must be fitted.

To examine the variation of $\mathrm{RC}$ with the length of the supposed contributing area using real data from El Cautivo runoff plots, we first determined the perimeter of the catchment of each plot. Then we calculated the successively larger real areas delimited by successive 10 -cm buffers in parallel to the trough.

To establish the catchment areas and soil surface components, a series of manual photogrammetric flights were carried out by means of a DJI Phantom 4 Pro drone carrying a highresolution, 1-inch sensor $(20 \mathrm{Mp})$. Images were taken at 3.5-5 $\mathrm{m}$ above ground level, combining nadir and oblique images with an estimated overlap of 80 and $70 \%$ (forward and side, respectively) to obtain an average of 596 images per experimental plot. Images were processed in Agisoft Metashape Pro (Agisoft LLC, Russia). Resolution ranged from 0.95 to 1.13 mm pixel ${ }^{-1}$ and 1.9 and $2.7 \mathrm{~mm} \mathrm{pixel}^{-1}$ for orthomosaics and the digital elevation model, respectively.

After removing most of the plants, using the Agisoft Metashape image classification software and then manually, the digital terrain model was processed to identify the catchment areas draining to the collectors (Hydrology Tools, ArcMap 10.8). Then, each catchment area was divided into parallel $10-\mathrm{cm}$ bands, parallel to the runoff collector (Multi-ring Buffer, QGIS 3.14). From the digital terrain model, the average slope of each catchment was also obtained (Zonal Statistics, ArcGis 10.8).

Thus, every regular increase in slope length corresponds to a different, but real, increase of contributing area. Then we calculated the RCs for every area (10 cm longer than the previous), plotted those RCs $v s$ the hillslope length, and fitted a potential curve. In a first step, we did this not for any concrete event but for the average and for the maximum RCs of every rain type and every biocrust type to verify the quality of the fittings and obtain a graphical reference of the mRL values.

We determined the cover of vascular plants, biocrusts, and bare soil in each plot by adding the segments occupied by every 

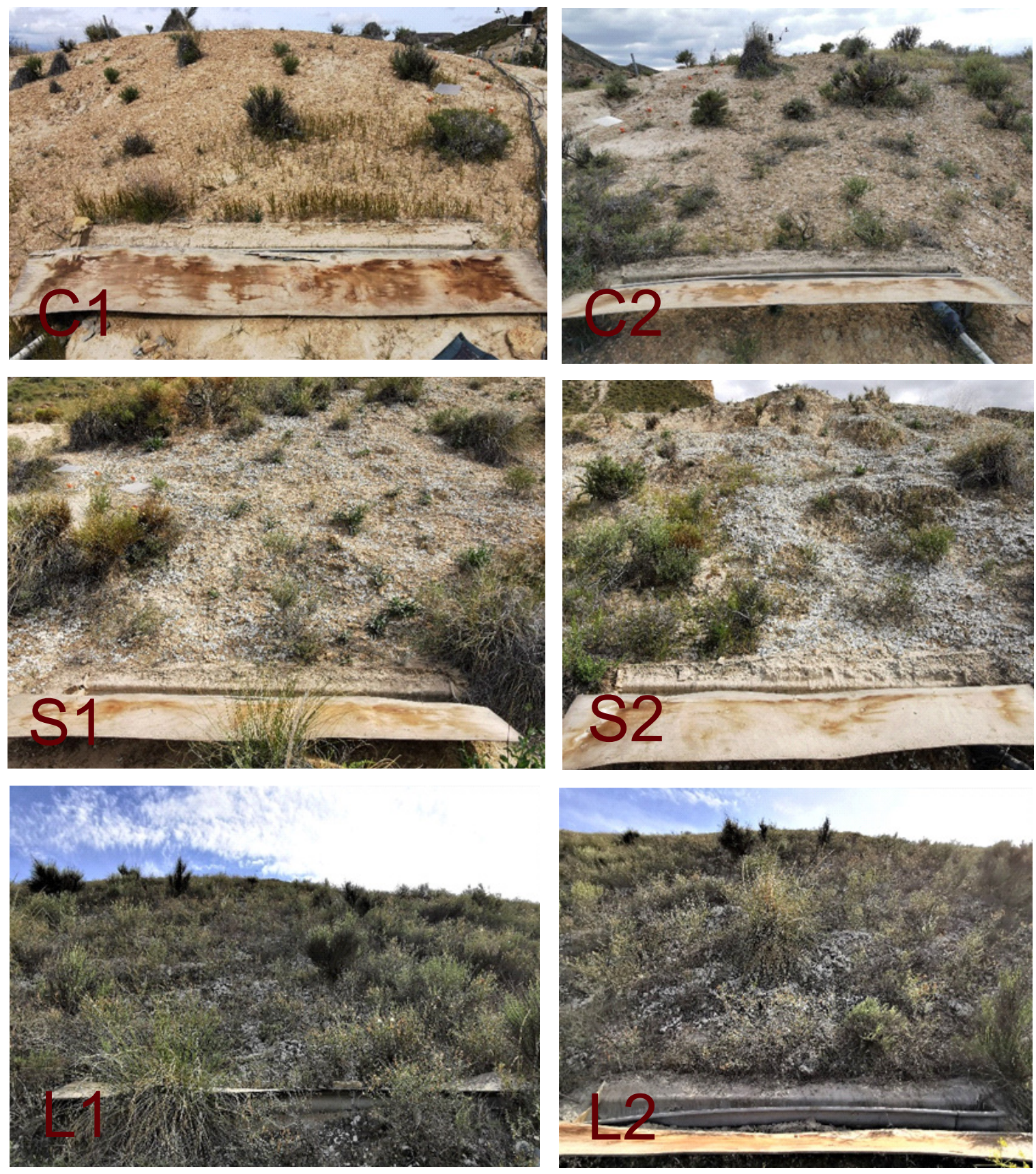

Fig. 1. El Cautivo hillslope scale open runoff plots.

surface type at $1 \mathrm{~mm}$ resolution in transects along the catchment area drawn on the plot orthophotomap (to avoid trampling the plots). The length occupied by each type of coverage in relation to the total length of the transect was directly considered its cover percentage.

We used Equation (4) to calculate mRL directly for every rain and runoff event of each MIT (24, 12 and 1 hour). We carried out generalized linear modelling analyses to test for differences in $\mathrm{mRL}$ according to two factors and their interaction: rain classes (seven categories) and biocrust types (three). We explored the instantaneous rain intensity and the rain duration as covariates; the volume of precipitation was not included due to its redundancy with the rain class factor. To account for the differences among individual plots, catchment areas, slope angles, the covers of vascular plants, biocrusts, and bare soil, and the covers of vascular plants in the catchment areas delimited by $1 \mathrm{~m}, 2 \mathrm{~m}$, and $8 \mathrm{~m}$ upstream of the channel were also initially considered as covariates. Instantaneous rain intensity was calculated for every rainfall record (rainfall volume input divided by the difference between the time of that record and the time of the previous), and the data used here were the average and the maximum intensities for each event. Then, we reduced the number of covariates, taking into account their interrelationships, the available statistical power, and the significance levels that the covariates reached in preliminary, tentative analyses (see in Results). To perform these analyses, we selected a gamma data distribution and log as link function, including the records having $\mathrm{mRL}$ larger than zero, and used Statistica 7.1 software (StatSoft, Hamburg, Germany). 


\section{RESULTS}

\section{Features of runoff plots and rainfall events}

The characteristics of the runoff plots determined by analysing the drone images are shown in Table 1.

The duration, volume, intensity, and number of events for every rain type and every MIT are summarized in Table 2.

The regression coefficient between runoff and rainfall was quite similar for the events from the three MITs in every plot and slightly higher for the 1-hour MIT (0.630 on average vs 0.572 and 0.575 for the 24- and 12-hour MITs, respectively). Thus, we show the analyses with the 1-hour MIT, which, moreover, produces the largest number of events. The larger maximum rain intensity belonged to event class 5 (although the average intensities were not very different among MITs). The very large maximum intensity recorded in event class 1 when we used MIT 1 lasted 5 seconds and did not generate runoff.
Every pair of plots on the same kind of surface have a similar hydrological behaviour (Fig. 2), except for Squam biocrust. The shape of the point clouds in Fig. 2, resembling a partially open "fan" and curved upwards, shows the increasing effect of rain intensity and antecedent soil moisture as the precipitation volume increases. The amplitude of these "fans" shows the variance due to the rainfall type and timing. Additionally, we can obtain an idea about the effect of biocrust type on runoff by comparing the scaling in the $y$-axes.

Rainfall volume to start runoff progressively increases through biocrust types; it is short at Cyano, medium at Squam, and larger at Lepra. Considering all the plots and events of the 1-hour MIT, we found 2336 cases (sum of events including all the plots) with an mRL equal to zero and 21 with an mRL larger than zero within the rainfall class 1 . The same values were, respectively, 1029 and 70 for class 2; 305 and 121 for class 3; 181 and 245 for class $4 ; 85$ and 215 for class $5 ; 9$ and 81 for class 6 ; and 3 and 33 for class 7 .

Table 1. Features of the runoff plots used at the El Cautivo field site. Biocrust types are described in the main text. Area is the contributing area according topography $\left(\mathrm{m}^{2}\right)$. Length is the slope length of the area $(\mathrm{m})$. Slope is the average slope angle (degrees). Aspect is the general orientation (degrees in eastward direction). Covers are given as \%. Plant cover $1 \mathrm{~m}$ is the plant cover in the first meter upstream from the collector.

\begin{tabular}{lccccccccc}
\hline Plot & Biocrust & Area & Length & Slope & $\begin{array}{c}\text { Aspect } \\
\text { eastward }\end{array}$ & $\begin{array}{c}\text { Plant } \\
\text { cover }\end{array}$ & $\begin{array}{c}\text { Biocrust } \\
\text { cover }\end{array}$ & $\begin{array}{c}\text { Bare } \\
\text { cover }\end{array}$ & $\begin{array}{c}\text { Plant } \\
\text { cover 1m }\end{array}$ \\
\hline C1 & Cyano & 8.59 & 7.04 & 24.46 & 265 & 22.13 & 73.65 & 4.22 & 8.45 \\
C2 & Cyano & 10.79 & 6.19 & 16.79 & 84 & 8.58 & 81.63 & 9.79 & 5.87 \\
S1 & Squam & 19.15 & 13.64 & 33.18 & 7 & 27.04 & 70.20 & 2.76 & 14.24 \\
S2 & Squam & 22.38 & 9.72 & 43.59 & 4 & 11.58 & 69.00 & 19.42 & 27.30 \\
L1 & Lepra & 21.91 & 12.56 & 40.92 & 20 & 30.95 & 57.94 & 11.12 & 5.59 \\
L2 & Lepra & 31.08 & 11.44 & 41.96 & 22 & 34.57 & 54.05 & 11.37 & 49.10 \\
\hline
\end{tabular}

Table 2. Features of the rainfall events; averages from the three rain-gauges. Average and maximum duration are in days; average volume is rainfall in $\mathrm{mm}$; average and maximum intensity are in $\mathrm{mm} /$ hour. *Remember that maximum intensity lasted only 5 seconds.

\begin{tabular}{|c|c|c|c|c|c|c|c|c|}
\hline & Rain class & $\begin{array}{c}1 \\
>0-1 \mathrm{~mm} \\
\end{array}$ & $\begin{array}{c}2 \\
>1-3 \mathrm{~mm} \\
\end{array}$ & $\begin{array}{c}3 \\
>3-5 \mathrm{~mm} \\
\end{array}$ & $\begin{array}{c}4 \\
>5-10 \mathrm{~mm} \\
\end{array}$ & $\begin{array}{c}5 \\
>10-20 \mathrm{~mm} \\
\end{array}$ & $\begin{array}{c}6 \\
>20-30 \mathrm{~mm} \\
\end{array}$ & $\begin{array}{c}7 \\
>30 \mathrm{~mm} \\
\end{array}$ \\
\hline \multirow{6}{*}{ MIT $24 \mathrm{~h}$} & number of events & 199 & 72 & 31 & 42 & 52 & 21 & 19 \\
\hline & average duration, days & 0.33 & 0.65 & 0.80 & 1.18 & 1.33 & 1.73 & 2.68 \\
\hline & maximum duration, days & 3.26 & 4.16 & 3.25 & 8.93 & 4.60 & 4.66 & 6.86 \\
\hline & average volume, $\mathrm{mm}$ & 0.32 & 1.72 & 3.63 & 6.58 & 13.13 & 23.31 & 39.07 \\
\hline & average intensity, $\mathrm{mm} / \mathrm{h}$ & 5.75 & 0.64 & 0.40 & 0.85 & 0.96 & 1.22 & 1.21 \\
\hline & maximum intensity, $\mathrm{mm} / \mathrm{h}$ & $542.99 *$ & 12.08 & 1.15 & 13.17 & 8.48 & 7.06 & 7.13 \\
\hline \multirow{6}{*}{ MIT $12 \mathrm{~h}$} & number of events & 323 & 94 & 36 & 48 & 54 & 22 & 16 \\
\hline & average duration, days & 0.14 & 0.29 & 0.50 & 0.56 & 0.80 & 1.17 & 1.26 \\
\hline & maximum duration, days & 0.86 & 0.90 & 1.94 & 2.02 & 2.96 & 3.62 & 2.61 \\
\hline & average volume, $\mathrm{mm}$ & 0.27 & 1.66 & 3.74 & 6.53 & 12.93 & 24.69 & 34.83 \\
\hline & average intensity, $\mathrm{mm} / \mathrm{h}$ & 1.37 & 1.06 & 0.48 & 1.03 & 1.23 & 1.56 & 1.74 \\
\hline & maximum intensity, $\mathrm{mm} / \mathrm{h}$ & 20.27 & 12.08 & 1.26 & 13.17 & 8.48 & 7.06 & 7.13 \\
\hline \multirow{6}{*}{ MIT $1 \mathrm{~h}$} & number of events & 1014 & 184 & 71 & 71 & 50 & 15 & 6 \\
\hline & average duration, days & 0.02 & 0.06 & 0.10 & 0.16 & 0.25 & 0.30 & 0.39 \\
\hline & maximum duration, days & 0.12 & 0.27 & 0.34 & 0.41 & 0.76 & 0.74 & 0.68 \\
\hline & average volume, $\mathrm{mm}$ & 0.22 & 1.64 & 3.62 & 6.76 & 13.38 & 23.55 & 36.16 \\
\hline & average intensity, $\mathrm{mm} / \mathrm{h}$ & 1.57 & 2.33 & 2.73 & 3.07 & 3.67 & 5.51 & 4.61 \\
\hline & maximum intensity, $\mathrm{mm} / \mathrm{h}$ & 20.27 & 18.41 & 19.44 & 18.61 & 40.88 & 20.12 & 9.16 \\
\hline
\end{tabular}



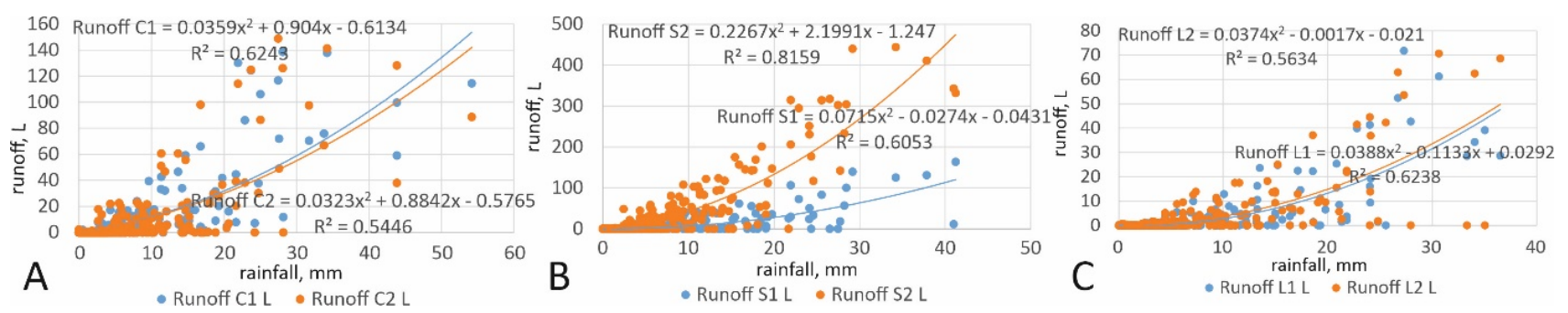

Fig. 2. Runoff ( $y$-axis in litres) $v s$ rainfall ( $x$-axis, mm). Data are the total of each event, using the 1411 events distinguished by the 1-hour MIT. Every graph shows the two plots of the same biocrust type. Graphs A, B, and C correspond to Cyano, Squam, and Lepra, respectively, and are presented in ascending successional order. Note that the scales of the $y$-axes are different.

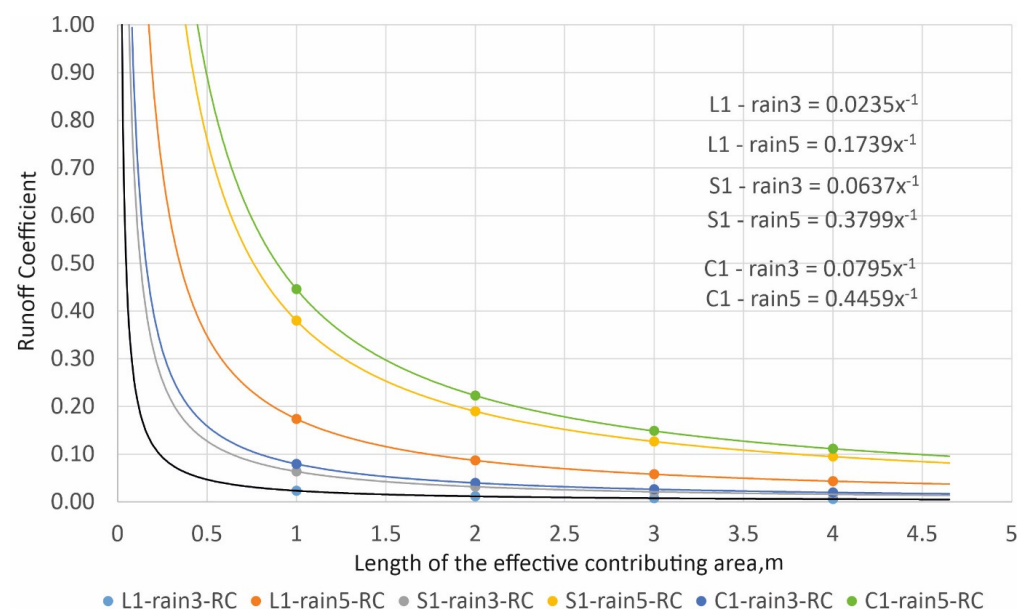

Fig. 3. Examples of hyperbolas relating to the $\mathrm{RC}$ with the length of the supposed effective contributing area. For each plot, we use the mean runoff and precipitation of all events of the rainfall classes $3(>3-5 \mathrm{~mm})$ and $5(>10-20 \mathrm{~mm})$, generated with the 1-hour MIT. For every pair of rain and runoff data points, we successively assumed four rectangular, nested, effective contributing areas having the length of the channel as width and 1, 2,3, and $4 \mathrm{~m}$ as length. All hyperbolas are asymptotic with respect to the $\mathrm{Y}$ axis, thus, a length for the effective contributing area that makes $\mathrm{RC}=1$ always exists. A $\mathrm{RC}$ value $>1$ or $>>1$ indicates that the assumed length for the contributing area is less or much less than the real one.

\section{Theoretical curves of decrease of $\mathrm{RC}$ according to regular increase of contributing area}

The RC hyperbolas differed in the distance of the vertex from the origin of coordinates, which vary according to surface types, topography, antecedent soil moisture, rainfall types, etc. Fig. 3 shows some examples for theoretical regularly increasing areas. Even for a surface with high infiltration (with the hyperbola vertex close to the coordinates' origin), a positive slope length for which $\mathrm{RC}=1$ (an $\mathrm{mRL}$ value) always exists.

In these theoretical curves, the greater the MIT, the greater the RCs and the further the hyperbola vertex were from the origin of the coordinates, because of the greater proportion of large events (Table 2).

\section{Goodness of fit of the real drainage areas to the theoretical hyperbolas}

When we used successive bands of the real catchment areas of every plot to exam the relationship between RC and increasing contributing areas, the fit of the hyperbolas (Fig. 4) was very good, because the plots' catchments are vaguely smooth and rectangular, at least along the hillslope meters closer to the channel.

The abscissa corresponding to the point where the hyperbola crosses the value 1 of ordinates is the mRL. These curves show that for any surface and rainfall, maximum RCs are much larger than average. Therefore, for a case in which a curve refers to a set of events, it is crucial to specify whether the used mRL is based in the maximum runoff peaks, the average runoff, or any other runoff parameter. The maximum mRL (Fig. 4) was between 3.3 and $4 \mathrm{~m}$ at Cyano, about $2.2 \mathrm{~m}$ at S1 (although it was about $7.5 \mathrm{~m}$ at S2), and between 1.0 and $1.5 \mathrm{~m}$ at Lepra.

Using the 12-hour MIT and 24-hour MIT, the number of events changes, as well as the proportion of events belonging to every rainfall class. However, the goodness of fit and the general features of the results are practically the same as those shown in Fig. 4.

Fig. 5 shows that runoff peaks were different in every biocrust, as well as for every rain class. Note that the largest RCs are produced by rain class 5 .

These graphs offer an understanding of the relationship between RC and contributing area, verify the goodness of the fit, and provide a graphical value of mRL. Once a good fit was established, we analysed mRL data calculated event by event by using Equation (4).

\section{Analysis of $m R L$ with regard to rainfall, surface and topography features}

The analyses showed significant differences in $\mathrm{mRL}$ according to all of the factors and included covariates. Rain duration and the cover of bare soil were removed because they were not significant when analysed along with the other variables. The biocrust cover was also removed because it shows a clear negative relationship $\left(\mathrm{R}^{2}=0.86\right)$ with plant cover. The plant cover within 1,2 and $8 \mathrm{~m}$ upstream from the runoff collector, although often independent from the general plant cover, were 
Plot C1

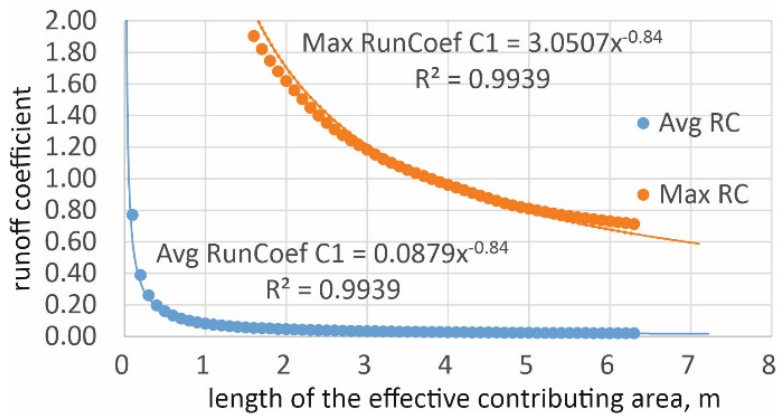

Plot S1

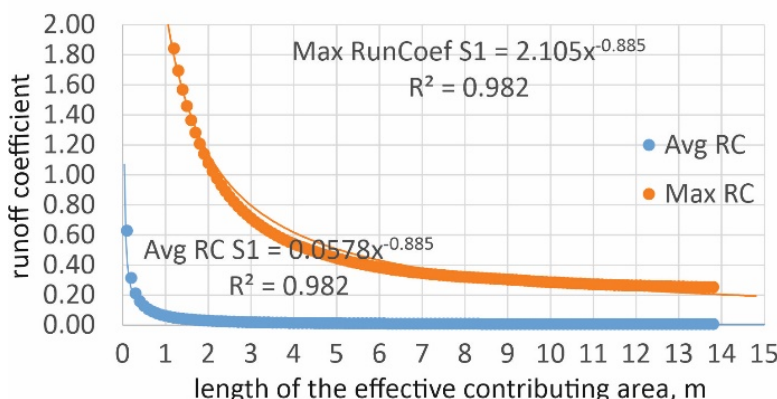

Plot L1

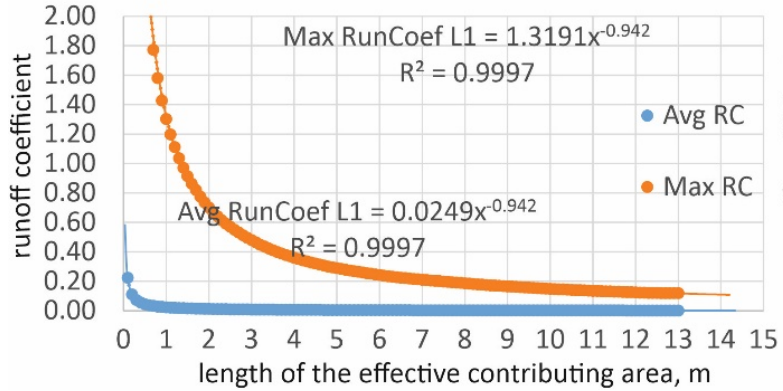

Plot C2

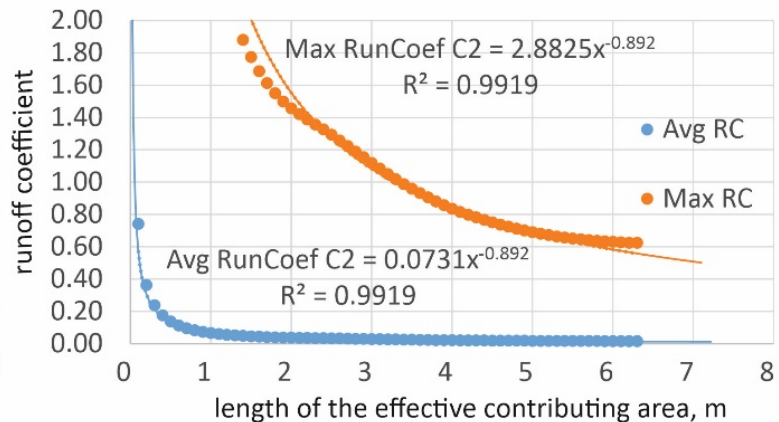

Plot S2

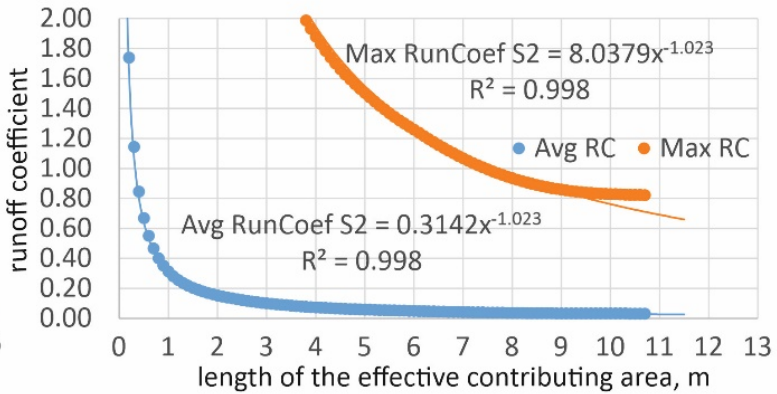

Plot L2

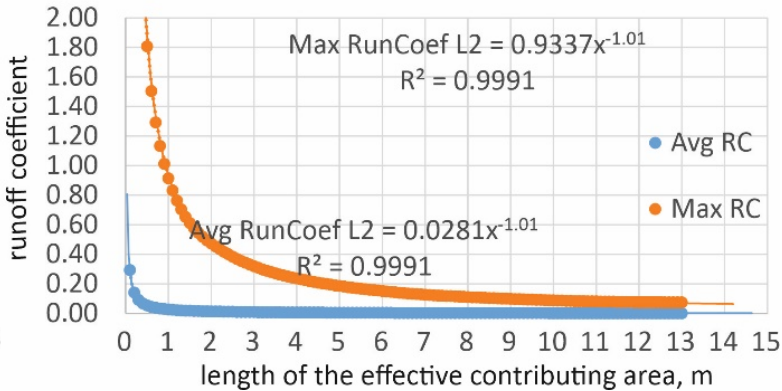

Fig. 4. Difference between the average and maximum runoff. Hyperbolas fitting the variation of RC when successively larger portions of the real topographic catchment of every plot, delimited by parallel lines spaced $10 \mathrm{~cm}$ from each other, are assumed to be the effective contributing areas. Data using the 1-hour MIT. All hyperbolas are asymptotic with respect to the Y axis, thus, a length for the effective contributing area that makes $\mathrm{RC}=1$ always exists. A RC value $>1$ or $>>1$ indicates that the assumed length for the contributing area is less or much less than the real one.
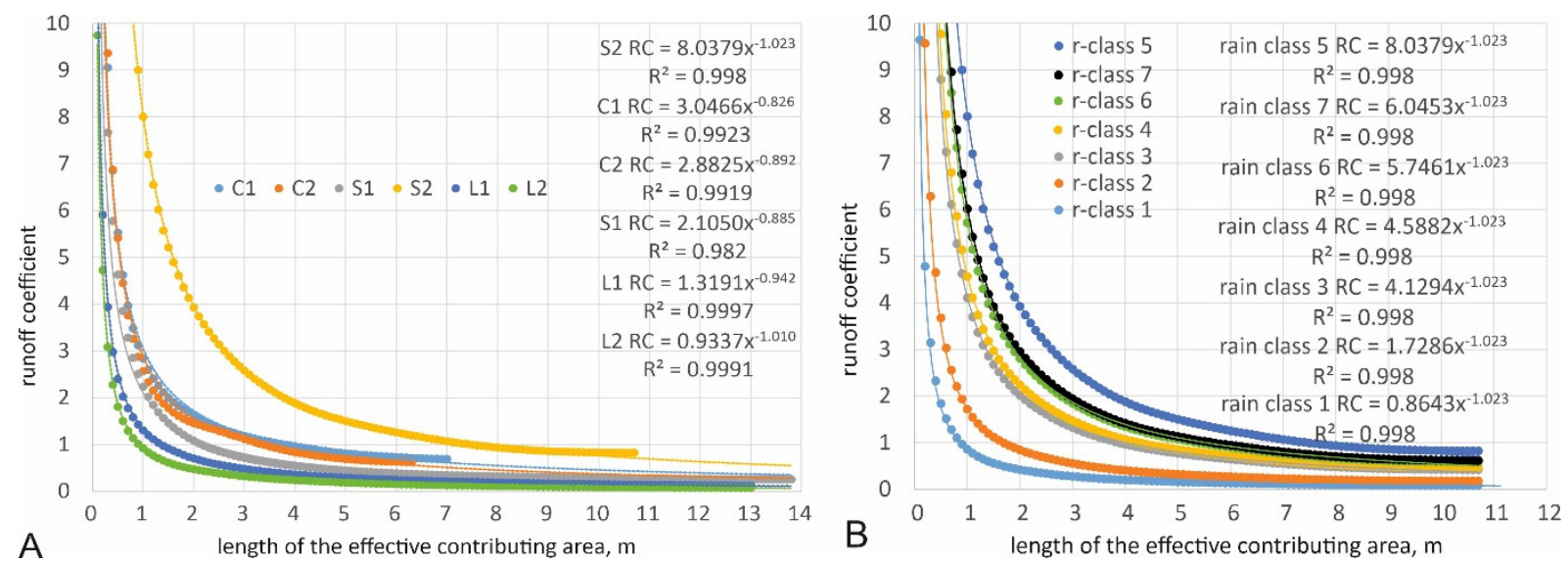

Fig. 5. Graph A: Hyperbolas of RC $v s$ contributing area for each plot using the maximum RC of the entire event series and the bands of the real topographical catchments. Graph B: Hyperbolas using the maximum RC of the event classes in the most responsive runoff plot (S2), and the bands of the real topographical catchments $\left(\mathrm{R}^{2}\right.$ are the same for all the rain classes because all the curves refer to the same plot and to the same increments of contributing area). Both graphs used data from the 1-hour MIT. All hyperbolas are asymptotic with respect to the $\mathrm{Y}$ axis, thus, a length for the effective contributing area that makes $\mathrm{RC}=1$ always exists. A $\mathrm{RC}$ value $>1$ or $>>1$ indicates that the assumed length for the contributing area is less or much less than the real one. 
also removed to gain statistical power and used in alternative analyses instead of the general plant cover. Thus, the final analysis included both factors (biocrust type and rain class) and their interaction, three covariates to account for the features of every particular plot (catchment area, slope, and plant cover), and the rain intensity as an additional covariate, because it is poorly related to the rainfall volume. Table 3 summarizes the results of the final analysis.

The mRL consistently increases when rainfall increases, and the differences between rain classes are often significant.
An mRL threshold in at about $3 \mathrm{~mm}$ of rainfall has been found (Fig. 6): At less than $3 \mathrm{~mm}$ of rainfall, the peaks of $\mathrm{mRL}$ never reached $10 \mathrm{~cm}$ (runoff was rare in rain classes 1 and 2 , but sometimes it occurred; see above).

The biocrust type significantly affected the mRL (Fig. 7A), and when we removed the data from plot $\mathrm{S} 2$, the mRL decreased along biocrust succession (Fig. 7B). However, the features of $\mathrm{S} 2$, with much larger runoff due to other factors (such as larger bare soil area and slope angle), deform the relationship between $\mathrm{mRL}$ and the successional sequence if $\mathrm{S} 2$ is included.

Table 3. Significance of the effects of the different factors, interactions, and covariates on mRL, according to hypothesis testing using generalized linear modelling.

\begin{tabular}{lcccc}
\hline Effect & $\begin{array}{c}\text { Degrees of } \\
\text { freedom }\end{array}$ & $\begin{array}{c}\text { Log- } \\
\text { likelihood }\end{array}$ & $\begin{array}{c}\text { Chi- } \\
\text { square }\end{array}$ & p \\
\hline Event class & 6 & -205.644 & 221.2202 & 0.000000 \\
Biocrust type & 2 & -164.662 & 81.9652 & 0.000000 \\
Event class $\times$ Biocrust type & 12 & -146.243 & 36.8361 & 0.000237 \\
Rain intensity & 1 & -476.893 & 56.0725 & 0.000000 \\
Catchment area & 1 & -464.168 & 25.4504 & 0.000000 \\
Slope angle & 1 & -456.728 & 14.8815 & 0.000114 \\
Plant cover & 1 & -316.254 & 280.9465 & 0.000000 \\
\hline
\end{tabular}

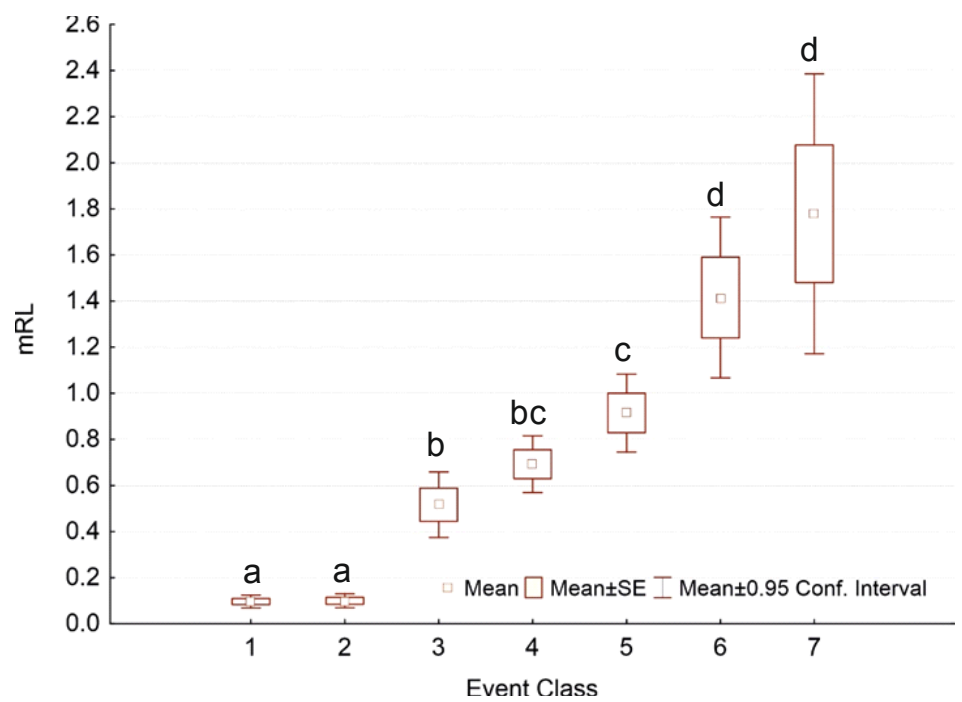

Fig. 6. Average mRL for the sets of events in every rain class produced using an MIT of 1 hour, including the data from all the plots. Different letters on the boxes indicate significant differences.
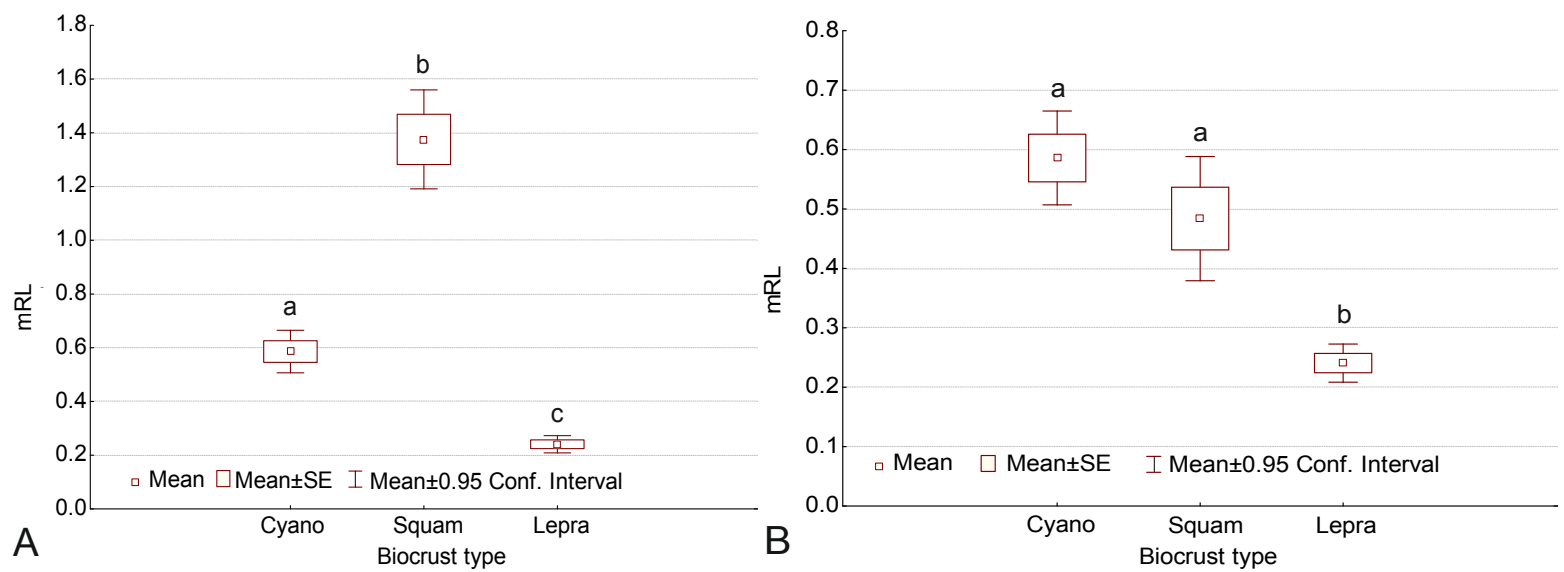

Fig. 7. Differences in $\mathrm{mRL}$ according to biocrust type. Graph A includes all the plots, and the differences are highly influenced by the larger runoff in plot S2. Graph B does not include the data from plot S2 and shows that infiltration increases along the ecological succession. Different letters on the boxes indicate significant differences. 


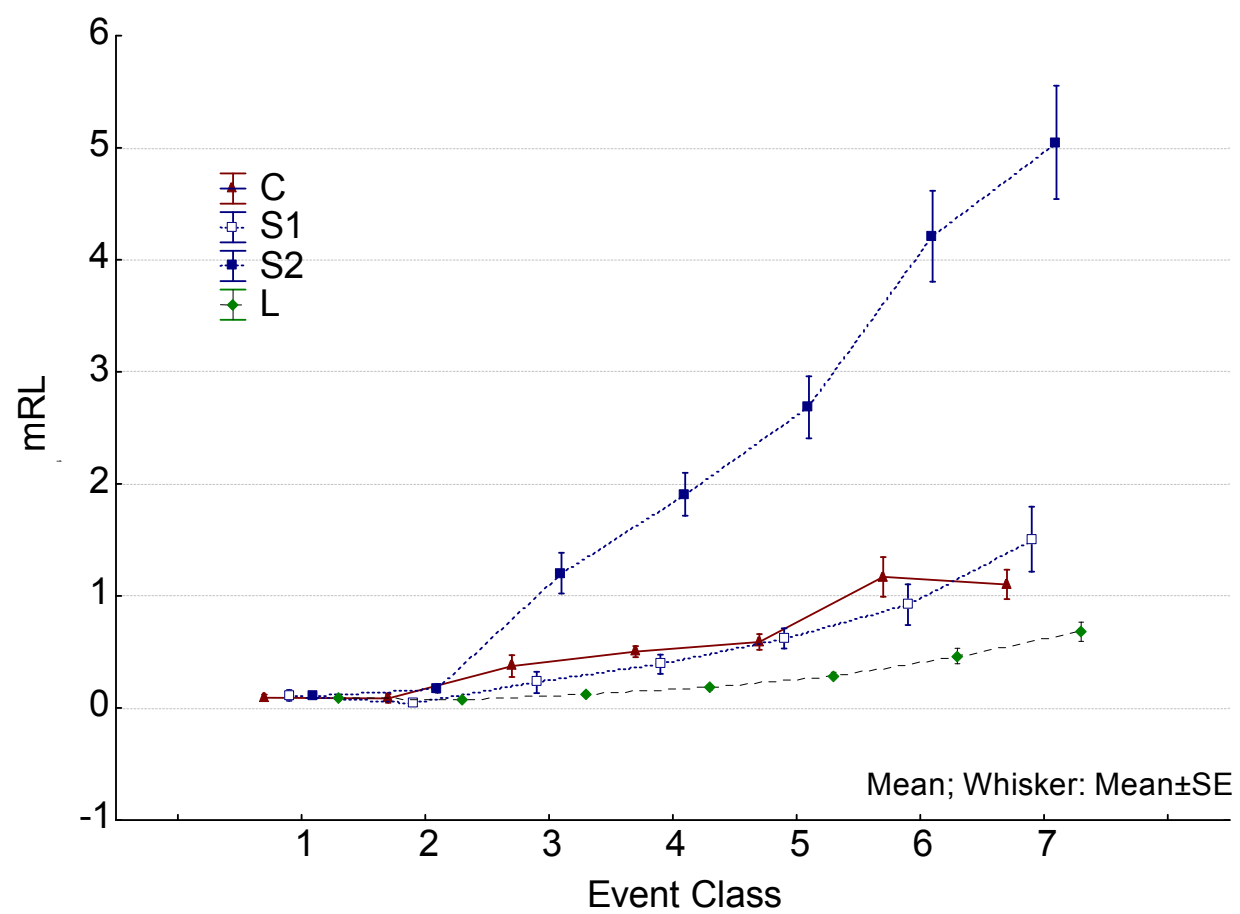

Fig. 8. Interaction between biocrust type and rain event class. Every line corresponds to a biocrust type, but for Squam the plots are shown separately because they behave quite differently. Except for plot S2, mRL decreases along biocrust succession. The threshold of mRL at $3 \mathrm{~mm}$ rainfall is distinguishable in this figure as well.

The interaction between biocrust type and rain class is shown in Fig. 8. The larger the rainfall, the larger the difference in $\mathrm{mRL}$ is among biocrusts. Biocrust type modulates the way in which the different rainfall classes affect runoff. However, the difference is also due to the slope and other causes such as plant and bare soil covers; the influence of plot S2 expanded the range of $\mathrm{mRL}$ along the event classes in the Squam biocrust.

Average rain intensity, contributing area and slope angle had a positive significant effect on $\mathrm{mRL}$, whereas plant cover had a negative significant effect (Table 3 ). When we carried out the alternative analyses replacing plant cover successively by the plant cover at 1,2 , or $8 \mathrm{~m}$ upstream of the channels, each cover showed a significant effect on $\mathrm{mRL}$.

The number of events decreases when the MIT increases and, whereas the duration of the events tends to increase exponentially when MIT increases, the rain intensity tends to decrease potentially when MIT increases. However, the generalized-linear-model results show the same pattern with all the MITs, with all the considered factors, interactions, and covariates of the final model being significant.

\section{DISCUSSION}

\section{RL and $\mathrm{mRL}$}

RL and $\mathrm{mRL}$ are different from hydrological connectivity. A stream or river can connect large distances; however, a certain concrete water volume usually does not cover all the connected distance because it stops at some point on the shore, infiltrates, evaporates, or is absorbed by plants. Similarly, when diffuse surface runoff (not concentrated in rills) occurs, the entire hillslope length can be hydrologically connected, but that does not necessarily mean that RL is the entire hillslope length. (However, it is certain that all the space covered by RL is connected.) If we progressively increase the length of the plot undergoing simulated rainfall, runoff volume increases until a certain plot length (Lázaro et al., 2015) because, beyond that length, all the water felt in the upper end of the plot infiltrates before reaching the collector. This threshold plot length is RL, a concept providing a measurement of the decay of RC as the drainage area increases. Connectivity is usually larger, sometimes drastically larger, than RL.

To explore and discuss the relationship of RL or mRL with the length slope factor (LSF) or potential sediment transport index (Moore and Burch, 1986), a parameter derived from the digital elevation model, could be interesting. The LSF is a surrogate that indicates the erosive potential of runoff, and its formula is $\mathrm{LSF}=(\mathrm{Xh} / 72.6)^{\mathrm{m}}$, where $X h$ is the horizontal length in meters of the slope and $m$ is the exponent of the slope variable, defined as $m=\varepsilon /(1+\varepsilon)$. The term $\varepsilon$ relates to erosion in the furrows and between furrows and is defined as $\varepsilon=$ $\sin \theta / 0.0896 \times\left(3 \times(\sin \theta)^{0.8}+0.56\right)$, where $\theta$ is the angle of the slope (McCool et al., 1997; Zhang et al., 2017). RL and mRL should relate closely to LSF because the (potential) transport capacity of sediments depends on runoff. Interestingly, LSF is a factor deduced from topography, but $\mathrm{mRL}$ is calculated from runoff and precipitation from specific events. In reality, both concepts are independent and complementary approximations. As a first tentative hypothesis, if we replace the slope length with the mRL in the LSF formula, the resulting potential sediment transport capacity would become actual capacity, that is, actual sediment transport if sediments are available. This could be verified empirically, and if so, mRL could be highly useful for a predictive erosion model where sediment availability is not a limiting factor.

As Lázaro et al (2015) discussed, the "flow length index" of Mayor et al. (2008) is conceptually comparable to RL. However, it does not include the incoming rainfall.

The slightly higher regression coefficient between runoff and rainfall for the 1-hour MIT we found agrees with the results of Molina-Sanchís et al. (2016).

We believe that $\mathrm{mRL}$ is a proxy of RL with general validity. By changing the rainfall or surface features, the parameter ' $a$ ' of Equation (1) changes, but it does not change the concepts or interpretations of the processes. The hyperbolic relationship we 
found between RC and real drainage area length (Fig. 4) is consistent with the potential decrease of RC experimentally determined by Lázaro et al (2015). In the experiments, the curves fit worse because different plots (although close, homogeneous, and under the same simulated rainfall) represented the different lengths. The goodness of the fits in Fig. 4, along with a certain irregularity of the shapes and micro-reliefs of our real drainage areas, show that our proposal is applicable in an extensive range of plots, because when we installed our plots in 2005, we did not look for 'ideal-like' hillslopes.

\section{Runoff on biocrusts at the El Cautivo field site}

As expected, the larger the rainfall, the larger the mRL. We found occasional runoff even in rain classes 1 and 2, which Rodríguez-Caballero et al. (2014) also found in the same study area. Despite an mRL value existing as long as the runoff is measurable, a clear threshold can be observed in the relationship between mRL and rainfall (Fig. 6). The way in which the rain class affected the $\mathrm{mRL}$ depended often on the biocrust type (Fig. 8). Lázaro et al. (2015) also observed that interaction: A threshold of runoff $v s$ rainfall is associated with a different rain class depending on the biocrust type.

The larger the rain intensity, the larger the mRL. This caused that the rain class 5 gave rise to the largest runoff coefficients (Fig. 5B), despite classes 6 and 7 involving larger rainfall volumes, as the intensity of class 5 was clearly larger when using MIT 1 (Table 2). This is consistent with what was previously stated in the same study area, under natural rainfall (RodríguezCaballero et al., 2014) and rain simulations (Lázaro et al., 2015). The same was found in other locations (Guan and Cao, 2019).

As expected, there were significant differences in $\mathrm{mRL}$ among biocrust types. Except for the Squam biocrust, the differences among plots belonging to the same biocrust type were much smaller than the differences among types (Fig. 2). The larger slope of plot $\mathrm{C} 1$ with regard to $\mathrm{C} 2$ was compensated by a lower contributing area. The lower plant cover of plot L1, particularly in the first meter upstream of the collector (Table 1), compensated for its smaller drainage area. However, the two plots at the Squam biocrust behaved differently. Much larger runoff was consistently recorded for plot S2 during the sampled period. It has larger slope, less plant cover, and much higher cover of bare soil, with its upper part eroded (Table 1). The slope angle in $\mathrm{S} 2$ is $45^{\circ}$ in the first $8 \mathrm{~m}$ upstream of the collector, which is relevant because the maximum recorded $\mathrm{mRL}$ was shorter than $8 \mathrm{~m}$. We did not find in the literature a slope threshold beyond which runoff disproportionately increases. However, where soil is silty, runoff is larger on bare than on biocrusted soil (Wei et al., 2015; Xiao et al., 2019). Soil texture seems determinant: In Tabernas' silty soils, biocrusts often generate less runoff than bare soil, but in the sandy soils of the Negev, biocrust shows threefold higher runoff than bare soil (Kidron, 1999). Chamizo et al. (2012a) and Lázaro et al. (2015) also found significant differences in runoff between biocrust types. Although cyanobacterial biocrusts tend to produce larger mRL, Rodríguez-Caballero et al. (2013) and Chamizo et al. (2012b) noted that the difference in runoff between cyanobacterial and lichenic biocrusts decreases to nothing as rainfall volume increases. Our result is consistent with Kidron et al. (2003), who found in Negev a substantial reduction in the RC from cyanobacterial to moss-dominated biocrust, explained by the lower amounts of extracellular polymeric substances and the higher roughness of moss-dominated biocrust. Small differences in the micro-relief already affect the runoff (Kidron,
2007). Our result partly agreed with Belnap (2006), who found two hydrological behaviours: Green algae and microfungi behave similarly to cyanobacteria, whereas bryophytes are similar to lichens.

Because the development of some biocrust types takes longer than that of others, and eventually one type is replaced by another (Lázaro et al., 2008), it is widely agreed that different biocrust types can be understood as successional steps (Belnap et al., 2006; Li et al., 2013; Rodríguez-Caballero et al., 2015), although some scholars do not regard different crust types as being necessarily successional stages (Kidron, 2019). In our area, the succession begins from Cyano and progresses to Squam and finally to Lepra (Lázaro et al., 2008). However, succession shows different speeds at different habitats and can stop at any point. It strongly depends on the microclimate, mainly on sun radiation and water availability. Where there are not conditions for development of lichens or mosses, Cyano can be almost permanent on a human life timescale.

Except for plot S2, our results show that infiltration tends to increase along biocrust succession. This is consistent with our previous experiments and with Gypser et al. (2016). Although biocrusts are often considered runoff sources (Cantón et al., 2002; Rodríguez-Caballero et al., 2018), their RC is generally lower than that of bare soil with physical crust (Eldridge et al., 2020) because biocrust succession progressively increases water retention (Gypser et al., 2016) and soil moisture (Chamizo et al., 2013). This increase of infiltration along succession is due to multiple factors, including (i) the effect of pore clogging increasing runoff in the early successional stages, favoured by cyanobacterial exopolysaccharides (Kidron et al., 1999); (ii) the increase of surface roughness increasing infiltration as the succession progresses (Chamizo et al., 2010; Kidron, 2007; Rodríguez-Caballero et al., 2012); and (iii) the larger proportion of mosses and vascular plants in the latest-successional biocrust (Lázaro et al., 2008), because mosses show larger infiltration capacity than do lichens (Fischer et al., 2014). In addition, plants, which develop progressively, are the main runoff sinks (Minea et al., 2018; Solé-Benet et al., 1997). Hydrological changes associated with successional stages have also been found in more mesic and larger vegetation including biocrusts (Lichner et al., 2012).

Comparable data on RL from other areas are scarce. Kidron (2011) reported an average RL of $5.0 \mathrm{~m}$, while Kidron and Yair (1997) estimated a length of 7 to $10 \mathrm{~m}$ for the effective contributing area in the case of the peak runoff produced at the end of the heaviest storm, when the biocrust was already saturated, in their most responsive plot, which had only $10 \%$ of plant cover and a relatively smooth biocrust. This length is close ourmaximum mRLvalue, which reached $7.5 \mathrm{~m}$ in our most responsive plot.

To our knowledge, this is the first study on the hydrological behaviour of the Lepra biocrust. Chamizo et al. (2012a; 2012b) and Lázaro et al. (2015) did not include Lepra to avoid severe alterations, as its typical large slope angle generates significant challenges in the experiments. This is interesting because Lepra is the permanent biocrust community that occupies the plant interspaces in non-eroded mature grassland or scrubland sites. Furthermore, because the sites chosen for the Lepra plots have relatively low grass cover, the runoff will be still lower in mature grasslands.

The mRL is consistently lower in Lepra over time, despite the slope, because of the greater plant cover (Minea et al., 2018) and number of small plant patches and annual plants. First, there is a larger number of plant roots acting as preferential infiltration routes; second, fine-grained plant patches are 
more efficient in reducing runoff than the coarse-grained ones (Bautista et al., 2007). In addition, soil porosity is larger under plants (Mora and Lázaro, 2014), and plants further increase infiltration by intercepting rainfall and producing stemflow (Jian et al., 2018). Furthermore, under alpha grass, biocrust rarely develops (Eldridge et al., 2010), but under plants such as Euzomodendron bourgaeanum, Helianthemum almeriense or Salsola genistoides, which are in the Lepra plots, biocrust (which favours runoff) is much more frequent than the $20 \%$ of cases that Kidron (2015) found under the canopy at Nizana (Israel). This occurs because the canopies of these species are less dense or more separated from the ground.

We found a positive relationship of $\mathrm{mRL}$ with slope, consistent in time and space in Cyano and Squam. This agrees with Chamizo et al. (2012b), who found, in the same study area, that the effect of slope might be irrelevant at the microplot scale, but is important at the small hillslope scale. However, the effect of slope was mainly due to the S2 plot. This slope effect is logical but its significance is relatively unexpected here due to (i) the opposite effect of the vegetation in the Lepra plots; and, (ii) the relatively higher $\mathrm{RC}$ of the Cyano biocrust (Alexander and Calvo, 1990; Chamizo et al., 2012a) having plots of lower steepness. Cerdá and García-Fayos (1997) found a positive relationship between slope and runoff initiation and sediment yield, but not between slope and runoff volume.

The effect of the catchment area was significant, despite the effective contributing area in most plots usually being much smaller than the topographic one. This was relatively unexpected because it only accounted for about $1 \%$ of the mRL variance. The effective contributing area would be the one delimited by RL. It is expected that an area longer than the RL would have little effect on runoff. However, it does have some effect: The rain falling above the RL but into a distance of up 2RL, although it does not reach the collector, increases soil moisture in the part of the plot delimited by RL, therefore increasing the RC. Additionally, the factor area was significant because the mean area of the Lepra plots was the largest, although the lowest runoff was recorded. In any case, the effect of the drainage area is fuzzy in this design. For example, the area of L2 is $50 \%$ larger than that of L1, and both slopes are similar. However, the plant cover of L2 is also larger (mainly in the first meter upstream of the channel), and the runoff is similar.

\section{CONCLUSIONS}

The mRL, a new parameter to characterize the runoff, is defined here as the hillslope length of the supposed effective contributing area that makes the $\mathrm{RC}=1$. It is quantitative, easy to calculate from runoff plots, and does not require the contributing area: It is a function of the runoff, precipitation, and the width of the runoff plot. Furthermore, mRL coincides with the coefficient of the hyperbola relating to the decrease of the RC as the contributing area increases. Because the hyperbola equation has only one coefficient, the concept of mRL enables knowing the whole hyperbole for any couple of runoff and rainfall values (if the shape or the relief of the plot catchment is not very irregular). We propose $\mathrm{mRL}$ as a proxy of $\mathrm{RL}$ and discuss its relationships with hydrological conductivity and the length slope factor.

We completed an mRL-based hydrological study with 10 years of runoff data from six open plots at a (small) hillslope scale including three biocrust types, in a badlands area of the Tabernas Desert (semiarid southeast Spain). The results show that the main features of rainfall affecting runoff (volume and intensity), as well as those of the surface (biocrust type and plant cover) and those of topography (contributing area and slope angle), determined mRL. Different biocrusts had different mRLs and whereas rainfall, area, and slope had a positive relationship with $\mathrm{mRL}$, plant cover had a negative relationship.

Acknowledgements. Funding: This study was started in the context of the research projects PECOS (REN200304570/GLO) and PREVEA (CGL2007-63258/BOS), both funded by the Spanish National Plan for RD\&I and by the European ERDF Funds (European Regional Development Fund), and continued during the project SCIN (Soil Crust InterNational, PRI-PIMBDV-2011-0874, European project of ERA-NET BIODIVERSA, the Spanish team being funded by the Spanish Ministry of Economy and Competitiveness). The work was finally supported and culminated by the DINCOS project (CGL2016-78075-P, Spanish State Programme for Scientific Research) and by the European ERDF Funds (European Regional Development Fund). Consuelo Rubio's participation was possible thanks to the contract as a doctoral student FPU18 / 00035. Dr. Javier Barbero advised us on mathematical issues.

Special thanks: This research was kindly facilitated by the Viciana brothers, landowners of the El Cautivo field site.

\section{REFERENCES}

Agassi, M., Ben-Hur, M., 1991. Effect of slope length, aspect and phosphogypsum on runoff and erosion from steep slopes. Aust. J. Soil Res., 29, 2, 197-207.

Alexander, R.W., Calvo, A., 1990. The influence of lichens on slope processes in some Spanish badlands. In: Thornes, J.B. (Ed.): Vegetation and Erosion: Processes and Environments. Wiley, New York, pp. 385-398.

Alexander, R.W., Harvey, A.M., Calvo-Cases, A., James, P.A., Cerda, A., 1994. Natural stabilisation mechanisms on badlands slopes: Tabernas, Almería, Spain. In: Millington, A.C., Pye, K. (Eds.): Environmental Change in Drylands: Biogeographical and Geomorphological Perspectives. Wiley, Chichester, pp. 85-111.

Alexander, R.W., Calvo-Cases, A., Arnau-Rosalén, E., Mather, A.E., Lázaro, R., 2008. Erosion and stabilization sequences in relation to base level changes in the El Cautivo badlands, SE Spain. Geomorphology, 100, 1-2, 83-90.

Arnau-Rosalén, E., Calvo-Cases, A., Boix-Fayos, C., Lavee, H., Sarah, P., 2008. Analysis of soil surface components patterns affecting runoff generation. An example of methods applied to Mediterranean hillslopes in Alicante (Spain). Geomorpholgy, 101, 4, 595-606.

Bautista, S., Mayor, Á. G., Bourakhouadar, J., Bellot, J., 2007. Plant spatial pattern predicts hillslope runoff and erosion in a semiarid Mediterranean landscape. Ecosystems, 10, 6, 987998.

Belnap, J., Lange, O. (Eds.), 2003. Biological Soil Crusts: Structure, Function and Management. Springer, Berlin, $506 \mathrm{p}$.

Belnap, J., 2006. The potential roles of biological soil crusts in dryland hydrologic cycles. Hydrol. Process., 20, 3159-3178.

Belnap, J., Phillips, S., Troxler, T., 2006. Soil lichen and moss cover and species richness can be highly dynamic: The effects of invasion by the annual exotic grass Bromus tectorum, precipitation, and temperature on biological soil crusts in SE Utah. App. Soil Ecol., 32, 1, 63-76.

Boix-Fayos, C., Martínez-Mena, M., Arnau-Rosalén, E., CalvoCases, A., Castillo, V., Albaladejo, J., 2006. Measuring soil erosion by field plots: Understanding the sources of varia- 
tion. Earth-Science Reviews, 78, 3-4, 267-285.

Bowker, M.A., Maestre, F.T., Escolar, C., 2010. Biological crusts as a model system for examining the biodiversityecosystem function relationship in soils. Soil Biology and Biochemistry, 42, 3, 405-517.

Büdel, B., 2003. Synopsis: comparative biogeography of soilcrust biota. In: Belnap, J., Lange, O. (Eds.): Biological Soil Crusts: Structure, Function and Management. Springer, Berlin, pp. 141-152.

Cantón, Y., Domingo, F., Solé-Benet, A., Puigdefábregas, J., 2002. Influence of soil surface types on the overall runoff of the Tabernas badlands (south-east Spain): field data and model approaches. Hydrol. Process., 16, 2621-2643.

Cantón, Y., Solé-Benet, A., Lázaro, R., 2003. Soilgeomorphology relations in gypsiferous materials of the Tabernas desert (Almería, SE Spain). Geoderma, 115, 193-222.

Cantón, Y., Del Barrio, G., Solé-Benet, A., Lázaro, R., 2004. Topographic controls on the spatial distribution of ground cover in a semiarid badlands area. Catena, 55, 341-365.

Castillo, V.M., Gómez-Plaza, A., Martínez-Mena, M., 2003. The role of antecedent soil water content in the runoff response of semiarid catchments: a simulation approach. J. Hydrol., 284, 114-130.

Cerdá, A., García-Fayos, P., 1997. The influence of slope angle on sediment, water and seed losses on badland landscapes. Geomorphology, 18, 77-90.

Chamizo, W., Rodríguez-Caballero, E., Miralles-Mellado, I., Afana, A., Lázaro, R., Domingo, F., Calvo-Cases, A., SoléBenet, A., Cantón, Y., 2010. Características de las costras físicas y biológicas del suelo con mayor influencia sobre la infiltración y la erosión en ecosistemas semiáridos. Pirineos, 165, 69-96.

Chamizo, S., Cantón, Y., Lázaro, R., Solé-Benet, A., Domingo, F., 2012a. Crust composition and disturbance drive infiltration through biological soil crusts in semiarid ecosystems. Ecosystems, 15, 1, 148-161.

Chamizo, S., Cantón, Y., Rodríguez-Caballero, E., Domingo, F., Escudero, A., 2012b. Runoff at contrasting scales in a semiarid ecosystem: A complex balance between biological soil crust features and rainfall characteristics. J. Hydrol., 452-453, 130-138.

Chamizo, S., Cantón, Y., Lázaro, R., Domingo, F., 2013. The role of biological soil crusts in soil moisture dynamics in two semiarid ecosystems with contrasting soil textures. J. Hydrol., 489, 74-84.

Chamizo, S., Belnap, J., Eldridge, D.J., Canton, Y., Malam Issa, O., 2016. The role of biocrusts in arid land hydrology. In: Weber, B., Büdel, B., Belnap, J. (Eds.): Biological Soil Crusts: An Organizing Principle in Drylands. Springer, pp. 321-346.

Eldridge, D.J., Bowker, M.A., Maestre, F.T., Alonso, P., Mau, R.L., Papadopoulos, J., Escudero, A., 2010. Interactive effects of three ecosystem engineers on infiltration in a semiarid Mediterranean grassland. Ecosystems, 13, 499-510.

Eldridge, D.J., Reed, S., Travers, S.K., Bowker, M.A., Maestre, F.T., Ding, J., Havrilla, C., Rodríguez-Caballero, E., Barger, N., Weber, B., Antoninka, A., Belnap, J., 2020. The pervasive and multifaceted influence of biocrusts on water in the world's drylands. Glob. Change Biol., 26, 10,6003-6014.

Fischer, T., Gypser, S., Subbotina, M., Veste, M., 2014. Synergic hydraulic and nutritional feedback mechanisms control surface patchiness of biological soil crusts on tertiary sands at a post-mining site. J. Hydrol. Hydromech., 62, 4, 293-302.

Guan, H., Cao, R., 2019. Effects of biocrusts and rainfall characteristics on runoff generation in the $\mathrm{Mu}$ Us Desert, northwest China. Hydrology Research, 50, 5, 1410-1423.

Gypser, S., Veste, M., Fischer, T., Lange, P., 2016. Infiltration and water retention of biological soil crusts on reclaimed soils of former open-cast lignite mining sites in Brandenburg, north-east Germany. J. Hydrol. Hydromech., 64, 1, 1-11.

Jian, S.Q., Zhang, X.L., Wu, Z.N., Hu, C.H. 2018. The effects of stemflow on redistributing precipitation and infiltration around shrubs. J. Hydrol. Hydromech., 66, 1, 79-86.

Kidron, G.J., Yair, A., 1997. Rainfall-runoff relationships over encrusted dune surface, Nizzana, western Negev Israel. Earth Surf. Process. Landf., 22, 1169-1184.

Kidron, G.J., 1999. Differential water distribution over dune slopes as affected by slope position and microbiotic crust, Negev Desert, Israel. Hydrological Processes, 13, 16651682.

Kidron, G.J., 2007. Milimeter-scale microrelief affecting runoff yield over microbiotic crust in the Negev Desert. Catena, 70, 266-273.

Kidron, G.J., 2011. Runoff generation and sediment yield on homogeneous dune slopes: scale effect and implications for analysis. Earth Surf. Process. Landf., 36, 1809-1824.

Kidron, G.J., 2015. Runoff and sediment yields from undercanopy shrubs in a biocrusted dunefield. Hydrological Processes, 30, 11, 1665-1675.

Kidron, G.J., 2019. Biocrust research: A critical view on eight common hydrological-related paradigms and dubious theses. Ecohydrology, 12, 2, e2061.

Kidron, G.J., Yaalon, D.H. Vonshak, A., 1999. Two causes for runoff initiation on microbiotic crusts: hydrophobicity and pore clogging. Soil Science, 164, 18-27.

Kidron, G.J., Yair, A., Vonshak, A., Abellovich, A., 2003. Microbiotic crust control of runoff generation on sand dunes in the Negev Desert. Water Resources Research, 39, SWC51-SWC55.

Lázaro, R., Alexander, R.W., Puigdefábregas, J., 2000. Cover distribution patterns of lichens, annuals and shrubs in the Tabernas Desert, Almería, Spain. In: Alexander, R.W., Millington, A.C. (Eds.): Vegetation Mapping: from Patch to Planet. Wiley, Chichester, pp.19-40.

Lázaro, R., Rodrigo, F.S., Gutiérrez, L., Domingo, F., Puigdefábregas, J., 2001. Analysis of a 30-year rainfall record (1967-1997) in semi-arid SE Spain for implications on vegetation. J. Arid Environ., 48, 373-395.

Lázaro, R., Rodríguez-Tamayo, M.L., Ordiales, R., Puigdefábregas, J., 2004. El Clima. In: Mota, J., Cabello, J., Cerrillo, M.I., Rodríguez-Tamayo, M.L. (Eds.): Subdesiertos de Almería: naturaleza de cine. Consejería de Medio Ambiente, Junta de Andalucía, Almería, pp. 63-79.

Lázaro, R., Cantón, Y., Solé-Benet, A., Bevan, J., Alexander, R., Sancho, L.G., Puigdefábregas, J., 2008. The influence of competition between lichen colonization and erosion on the evolution of soil surfaces in the Tabernas badlands (SE Spain) and its landscape effects. Geomorphology, 102, 252266.

Lázaro, R., Mora, J.L., 2014. Sediment content and chemical properties of water runoff on biocrusts in drylands. Biologia, 69, 11, 1539-1554.

Lázaro, R., Calvo-Cases, A., Lázaro, A., Molina, I., 2015. Effective run-off flow length over biological soil crusts on silty loam soils in drylands. Hydrological Processes, 29, 2534-2544.

Le Bissonnais, Y., Renaux, B., Delouche, H., 1995. Interactions between soil properties and moisture content in crust for- 
mation, runoff and interrill erosion from tilled loess soils. Catena, 25, 1-4, 33-46.

Li, X.R., Zhang, Z.S., Huang, L., Wang, X.P., 2013. Review of the ecohydrological processes and feedback mechanisms controlling sand-binding vegetation systems in sandy desert regions of China. Chin. Sci. Bull., 58, 1483-1496. DOI: 10.1007/s11434-012-5662-5

Lichner, L., Holko, L., Zhukova, N., Schacht, K., Rajkai, K., Fodor, N., Sándor, R., 2012. Plants and biological soil crust influence the hydrophysical parameters and water flow in an aeolian sandy soil. J. Hydrol. Hydromech., 60, 309-318.

Maestre, F.T., Bowker, M.A., Cantón, Y., Castillo-Monroy, A.P., Cortina, J., Escolar, C., Escudero, A., Lázaro, R., Martínez, I., 2011. Ecology and functional roles of biological soil crusts in semi-arid ecosystems of Spain. J. Arid Environ., 75, 1282-1291.

Maestre, F.T., Eldridge, D.J., Soliveres, S., Kéfi, S., DelgadoBaquerizo, M., Bowker, M.A., García-Palacios, P., Gaitán, J., Gallardo, A., Lázaro, R., and Berdugo, M., 2016. Structure and functioning of dryland ecosystems in a changing world. Annual Review of Ecology, Evolution, and Systematics, 47, 215-237.

Mayor, A.G., Bautista, S., Small, E.E., Dixon, M., Bellot, J., 2008. Measurement of the connectivity of runoff source areas as determined by vegetation pattern and topography: a tool for assessing potential water and soil losses in drylands. Water Resour. Res., 44, 10, W10423.

Mayor, A., Bautista, S., Bellot, J., 2011. Scale-dependent variation in runoff and sediment yield in a semiarid Mediterranean catchment. Journal of Hydrology, 397, 128-135.

McCool, D., Foster, G., Weesies, G., 1997. Slope Length and Steepness Factors (LS). In: Renard, K., Foster, G., Weesies, G., McCool, D., Yoder, D. (Coord.): Predicting Soil Erosion by Water: A Guide to Conservation Planning with the Revised Universal Soil Loss Equation (RUSLE). Agriculture Handbook, No. 703, USDA, Washington, D.C., pp. 101142.

Minea, G., Ioana-Toroimac, G., Moroşanu, G., 2018. The dominant runoff processes on grassland hillslopes within different land uses of Romania - an experimental study. J. Hydrol. Hydromech., 67, 4, 297-304.

Molina-Sanchís, I., Lázaro, R., Arnau-Rosalén, E., Calvo-Cases A., 2016. Rainfall timing and runoff: The influence of the criterion for rain event separation. J. Hydrol. Hydromech., 64, 3, 226-236.

Moore, I.D., Burch, G.J., 1986. Physical basis of the lengthslope factor in the universal soil loss equation. Soil Sci. Soc. Am. J., 50, 5, 1294-1298.

Mora, J.L., Lázaro, R., 2014. Seasonal changes in bulk density under semiarid patchy vegetation: the soil beats. Geoderma, 235-236, 30-38.

Puigdefábregas, J., Solé, A., Gutierrez, L., del Barrio, G., Boer, M., 1999. Scales and processes of water and sediment redis- tribution in drylands: results from the Rambla Honda field site in southeast Spain. Earth-Science Reviews, 48, 39-70.

Puigdefábregas, J., 2005. The role of vegetation patterns in structuring runoff and sediment fluxes in drylands. Earth Surf. Process. Landf., 30, 133-147.

Rodríguez-Caballero, E., Cantón, Y., Chamizo, S., Afana, A., Solé-Benet, A., 2012. Effects of biological soil crusts on surface roughness and implications for runoff and erosion. Geomorphology, 145-146, 81-89.

Rodríguez-Caballero, E., Cantón, Y., Chamizo, S., Lázaro, R., Escudero, A., 2013. Soil loss and runoff in semiarid ecosystems: A complex interaction between biological soil crusts, micro-topography and hydrological drivers. Ecosystems, 16, 529-546.

Rodríguez-Caballero, E., Cantón, Y., Solé-Benet, A., Lazaro, R., 2014. Cross-scale interactions between surface components and rainfall properties. Non-linearities in the hydrological and erosive behaviour of semiarid catchments. Journal of Hydrology, 517, 815-825.

Rodríguez-Caballero, E., Aguilar, M.A., Cantón, Y., Chamizo, S., Aguilar, F.J., 2015. Swelling of biocrusts upon wetting induces changes in surface micro-topography. Soil Biology and Biochemistry, 82, 107-111.

Rodríguez-Caballero, E., Chamizo, S., Roncero-Ramos, B., Román, R., Cantón, Y., 2018. Runoff from biocrust: A vital resource for vegetation performance on Mediterranean steppes. Ecohydrology, 11, e1977.

Solé-Benet, A., Calvo-Cases, A., Cerdá, A., Lázaro, R., Pini, R., Barbero, J., 1997. Influences of micro-relief patterns and plant cover on runoff related processes in badlands from Tabernas (SE Spain). Catena, 31, 23-38.

Weber, B., Büdel, B., Belnap, J. (Eds.), 2016. Biological Soil Crusts: An Organizing Principle in Drylands. Springer, 549 p.

Wei, W., Yu, Y., Chen, L., 2015. Response of surface soil hydrology to the micro-pattern of biocrust in a dry-land loess environment, China. PLoS ONE, 10, 7, e0133565. DOI: 10.1371/journal. pone. 0133565

Xiao, B., Sun, F., Hu, K., Kidron, G.J., 2019. Biocrusts reduce surface soil infiltrability and impede soil water infiltration under tension and ponding conditions in dryland ecosystem. Journal of Hydrology, 568, 792-802.

Xu, X.L., Liu, W., Kong, Y.P., Zhang, K.L., Yue, B., Chen, J.D., 2009. Runoff and water erosion on road side-slopes: Effects of rainfall characteristics and slope length. Transportation Research Part D, 14, 497-501.

Zhang, H., Wei J., Yang, Q., Baartman, J.E.M., Gai, L., Yang, X., Li, S.Q., Yu, J., Ritsema, C.J., Geissen, V., 2017. An improved method for calculating slope length $(\lambda)$ and the LS parameters of the Revised Universal Soil Loss Equation for large watersheds. Geoderma, 308, 36-45.

Received 16 June 2021 Accepted 13 September 2021 